\title{
Measuring brain natriuretic peptide in suspected left ventricular systolic dysfunction in general practice: cross-sectional study
}

\author{
Martin J Landray, Richard Lehman, Ian Arnold
}

The prevalence of heart failure is increasing. ${ }^{1}$ Patients usually present to their general practitioner but a definitive diagnosis of left ventricular systolic dysfunction can only be achieved by cardiac imaging. Measuring plasma concentrations of brain natriuretic peptide has been advocated as a screening test that might reduce demands on cardiological services. ${ }^{2}$

We report the results of a community based study designed to investigate the effectiveness of measuring brain natriuretic peptide to diagnose left ventricular systolic dysfunction. The study was approved by the local research ethics committee.

\section{Participants, methods, and results}

General practitioners were invited to refer patients with suspected heart failure to our clinic. The results of transthoracic echocardiography were reported by a single, experienced observer (IA). Ischaemia was diagnosed if $\mathrm{Q}$ waves, bundle branch block, $\mathrm{T}$ wave inversions, or left ventricular hypertrophy were present on an electrocardiogram. Evidence of heart failure on a chest radiograph was defined as the presence of pulmonary oedema or cardiomegaly. Concentrations of brain natriuretic peptide were measured by immunoradiometric assay (Shionoria assay, Shionogi, Osaka, Japan) of plasma stored at $-70^{\circ} \mathrm{C}$. A concentration $>17.9 \mathrm{pg} / \mathrm{ml}$ was considered abnormal based on the results of a large study of left ventricular systolic dysfunction. $^{3}$

Altogether, 126 patients (68 men) with a mean age of 74.4 (SD 8.9) years were included in the study. Concentrations of the peptide were raised in the 40 patients with left ventricular systolic dysfunction (median concentration $79.4 \mathrm{pg} / \mathrm{ml}$, interquartile range 35.9-151.0) compared with those with normal ventricular systolic function $(26.7 \mathrm{pg} / \mathrm{ml}, 12.2-54.3$; $\mathrm{P}<0.001)$. A concentration $>17.9 \mathrm{pg} / \mathrm{ml}$ had a sensitivity of $88 \%$ and specificity of $34 \%$. Choosing different cut points did not improve the predictive characteristics: at $10 \mathrm{pg} / \mathrm{ml}$ sensitivity was $92 \%$ but specificity was $18 \%$, and at $76 \mathrm{pg} / \mathrm{ml}$ sensitivity was $66 \%$ and specificity $87 \%$.

The prior probability that a disease exists (its prevalence) and the extent to which a test result alters the chance of the disease existing determine whether further investigation is needed; this is the likelihood ratio of positive and negative tests. In the case of heart failure it is unlikely that a single positive test result will remove the need for further cardiac imaging before treatment is started. In contrast, a negative result may give a low posterior probability of disease so that further investigations are unnecessary.

The prevalence (or prior probability) of left ventricular systolic dysfunction in this study was $32 \%$; this is consistent with that reported in other studies. ${ }^{4}$ The likelihood ratio for a patient without a history of myocardial infarction, with negative results on chest radiography and electrocardiography, and with concentrations of brain natriuretic peptide below the cut off, individually and in combination, are shown in the table. Measuring the concentration of brain natriuretic peptide is the test with the lowest likelihood ratio for a negative test; thus it is the most useful. However, to be useful in clinical practice, this test must provide additional diagnostic information over that given by
Division of Medical Sciences, University of Birmingham, Birmingham BI5 2TH

Martin J Landray lecturer in clinical pharmacology

Hightown Surgery, Banbury

OX18 9DB

Richard Lehman general practice principal

Department of Medicine, Horton Hospital, Oxford Radcliffe Hospitals NHS Trust, Banbury OX16 9AL Ian Arnold consultant cardiologist

Correspondence to: R Lehman lehman@hightownl. demon.co.uk

BMJ 2000;320:985-6

Likelihood ratios for screening tests for left ventricular systolic dysfunction. Any combination of tests is defined as being positive if any of the individual components are positive

\begin{tabular}{|c|c|c|c|c|c|c|}
\hline Screening criteria & Specificity (\%) & Sensitivity (\%) & $\begin{array}{l}\text { Likelihood ratio if } \\
\text { test negative }\end{array}$ & $\begin{array}{l}\text { Likelihood ratio if } \\
\text { test positive }\end{array}$ & $\begin{array}{c}\text { Posterior } \\
\text { probability if test } \\
\text { negative* }(\%)\end{array}$ & $\begin{array}{c}\text { Posterior } \\
\text { probability if test } \\
\text { positive }^{\star}(\%)\end{array}$ \\
\hline Myocardial infarction† & 91 & 33 & 0.74 & 3.62 & 26 & 63 \\
\hline Electrocardiogram $\ddagger$ & 87 & 41 & 0.68 & 3.13 & 24 & 60 \\
\hline Chest radiograph§ & 45 & 65 & 0.79 & 1.17 & 27 & 36 \\
\hline Brain natriuretic peptidef & 34 & 88 & 0.35 & 1.32 & 15 & 38 \\
\hline \multicolumn{7}{|l|}{ Myocardial infarction or } \\
\hline Electrocardiogram & 82 & 61 & 0.48 & 3.29 & 19 & 61 \\
\hline Chest radiograph & 37 & 83 & 0.46 & 1.32 & 18 & 38 \\
\hline Brain natriuretic peptide & 27 & 90 & 0.38 & 1.23 & 15 & 37 \\
\hline \multicolumn{7}{|l|}{ Myocardial infarction or electrocardiogram or } \\
\hline Chest radiograph & 31 & 83 & 0.53 & 1.22 & 20 & 36 \\
\hline Brain natriuretic peptide & 22 & 91 & 0.42 & 1.17 & 16 & 35 \\
\hline $\begin{array}{l}\text { Myocardial infarction or chest } \\
\text { radiograph or brain natriuretic peptide }\end{array}$ & 14 & 91 & 0.62 & 1.06 & 23 & 33 \\
\hline Any test & 11 & 92 & 0.78 & 1.03 & 27 & 33 \\
\hline
\end{tabular}

*Prevalence (prior probability) of left ventricular systolic dysfunction assumed to be $32 \%$.

†Positive if there is a history of myocardial infarction.

$\ddagger$ Positive if $Q$ waves, bundle branch block, left ventricular hypertrophy, or T wave present.

$\S$ Positive if pulmonary oedema or cardiomegaly present.

IPositive if concentration $>17.9 \mathrm{pg} / \mathrm{ml}$. 
investigations that are more readily available, which in combination yield a minimum posterior probability of $20 \%$. Adding a test for brain natriuretic peptide to the determination of a patient's history of myocardial infarction in the diagnostic screening process reduces the posterior probability to $15 \%$.

\section{Comment}

There seems to be a small diagnostic advantage to measuring brain natriuretic peptide in addition to performing routine investigations. However, given the therapeutic and prognostic importance of correct diagnosis, most clinicians would find a 1 in 7 chance of left ventricular systolic dysfunction unacceptably high in a patient who has not been referred for echocardiography.

Recruitment to this study relied on the general practitioners making a provisional diagnosis of suspected heart failure, and results may be different in other settings, such as population based screening for asymptomatic left ventricular systolic dysfunction. Nevertheless this study suggests that introducing routine measurement of the plasma concentration of brain natriuretic peptide would be unlikely to improve the diagnosis of symptomatic left ventricular systolic dysfunction in the community.

We would like to thank Chris Teideman, Tim Lancaster and Alice Fuller for their help and support.

Contributors: IA and RL obtained funding for the study. All three authors designed the study protocol. IA and MJL ran the clinic for patients with suspected heart failure. MJL performed the statistical analysis and wrote the first draft of the paper. All three authors approved the final draft of the paper. Brain natriuretic peptide was measured by Dr M Morton, MRC Clinical Research Initiative in Heart Failure, University of Glasgow. RL will act as guarantor for the study.

Funding: This study was supported by a grant from the Oxford Region NHS research and development fund.

Competing interests: None declared.

1 Hoes AW, Mosterd A, Grobbee DE. An epidemic of heart failure? Recent evidence from Europe. Eur Heart J 1998;19(suppl L):2-8L.

2 Struthers AD. Further defining the role for natriuretic peptide levels in clinical practice. Eur Heart J 1999;20:712-4.

3 McDonagh TA, Robb SD, Murdoch DR, Morton JJ, Ford I, Morrison CE, et al. Biochemical detection of left-ventricular systolic dysfunction. Lancet 1998;351:9-13.

4 Wheeldon NM, MacDonald TM, Flucker CF, McKendrick AD, McDevitt DG, Struthers AD. Echocardiography in chronic heart failure in the community. QJ Med 1993;86:17-23.

(Accepted 13 December 1999)

\section{When I use a word Fortuitous-ambiguously inappropriate to describe maternal death?}

Irrespective of the pregnancy duration, if a women dies while pregnant or in the first six weeks thereafter, the death is classified as a maternal death. The reports on confidential inquiries into maternal deaths in England and Wales subclassify maternal deaths into direct, indirect, fortuitous, and unknown. Direct maternal deaths are when the death is as a direct result of an obstetric complication or intervention. An indirect maternal death is when death follows underlying maternal disease that is exacerbated by the pregnancy. Unknown maternal deaths occur in pregnancy or in the puerperium where no underlying cause is found. Fortuitous maternal deaths are deaths that occur from causes unrelated to the pregnancy and include violent deaths and suicide.

Maternal deaths unrelated to the pregnancy do occur and are important to classify, particularly with our increasing awareness of violence against women. However, is the adjective fortuitous the appropriate word to describe these deaths? Fortuitous is derived from and has the same meaning as the Latin word fortuitus, that takes place by chance or accident. The first documented written use of fortuitous occurred in the mid-seventeenth century and was from the pen of the Cambridge platonist Henry More in his book, The Argument against the Fortuitous Concourse of Atoms. A phrase he applied after Cicero (Concursus fortuitus) to the action whereby according to the atomic theory of Leucippus and Democritus the universe came into being. Strictly speaking, according to etymology, fortuitous is an appropriate adjective to use to describe a random event.

Another adjective, fortunate, meaning having good luck or coming by good luck sounds similar to fortuitous. The first documented appearance of the word fortunate in written English language is in Chaucer's Canterbury Tales (1390). Although the word is ultimately derived from Latin (fortunatus, provided with good fortune) it may originally have been borrowed from old French fortuné, happy, since Chaucer translated from French and probably was aware of the word from that source.

Classically, a fortuitous occurrence happens by chance and is not necessarily good or bad, while something that is fortunate is favourable but does not necessarily involve any element of chance or accident. Something that is fortuitous can also be fortunate, but unless it happened by chance or accident, the correct word to use is fortunate. This was the state of affairs until the 1920s. Robert Burchfield's The New Fowler's Modern English (third edition, Oxford University Press, 1996) reports that Henry Watson Fowler's Dictionary of Modern English Usage, published in 1926, noted that fortuitous had begun being used as a near synonym for fortunate. A fortuitous occurrence was something that happened by good fortune and not merely by chance or accident. Apparently Fowler considered this to be a malapropism as they sounded similar. Due to the similarity between the words the distinction between fortuitous and fortunate has become blurred and their frequent confusion has led to an increasing acceptance of fortuitous referring to something that happened by good chance. The Tenth Edition of the Concise Oxford Dictionary, the self confessed foremost authority on current English, defines fortuitous as something happening by chance rather than design or something happening by lucky chance.

A maternal death is never by lucky chance and the term fortuitous maternal death is too ambiguous. Maternal death unrelated to pregnancy is a more suitable term as it is both unambiguous and explanatory.

Graham Howarth associate professor in obstetrics and gynaecology, Pretoria, South Africa

We welcome articles of up to 600 words on topics such as A memorable patient, A paper that changed my practice, My most unfortunate mistake, or any other piece conveying instruction, pathos, or humour. If possible the article should be supplied on a disk. Permission is needed from the patient or a relative if an identifiable patient is referred to. We also welcome contributions for "Endpieces," consisting of quotations of up to 80 words (but most are considerably shorter) from any source, ancient or modern, which have appealed to the reader. 